\title{
DUTCH ELM DISEASE ARRIVES IN SASKATCHEWAN
}

Dutch Elm Disease (DED), a fatal disease that has destroyed millions of elms across North America, has arrived in Saskatchewan.

Infected elm trees were first discovered during a routine Saskatchewan Parks and Renewable Resources (SPRR) survey in Woodlawn Regional Park near Estevan in the summer of 1990. Approximately 3,600 trees were removed from the park over the winter in an attempt to control the spread of this devastating disease. Replanting began last spring. The infection probably started with a camper who, unaware of the potential hazard, brought infected elm firewood into the park.

In September 1991, elm trees infected with the disease were found near the communities of Carrot River, Rocanville, Grand Coulee and Shaunavon.

DED is caused by a fungus which disrupts the tree's water conducting system, usually killing the tree in a single season. The disease is spread by tiny beetles that breed in dead and dying elm wood, then fly to feed on healthy elms. Usually, the beetles fly only a short distance but on firewood transported by campers, the dis- ease can travel hundreds of miles.

To stop the spread of DED, public cooperation is essential. Homeowners can avoid the spread of the disease by keeping their elm trees well pruned and free of dead wood. Those buying, selling, cutting or transporting firewood should avoid elm wood. Everyone can help by keeping an eye out for the symptoms of DED and suspicious trees.

The first signs of the disease, wilting leaves on one or more branches, appear during late June and early July. The leaves then curl, turn brown and, usually, remain on the tree. Take a twig sample from the suspicious branch and look under the bark. The sapwood under the bark, normally white, will be streaked with brown if DED is present. Since other diseases can have similar symptoms, the diagnosis should be confirmed by a lab.

General DED information and sampling instructions are available at any SPRR office. For further information or to report a suspicious tree, contact SPRR's Forestry Branch in Prince Albert at 953-2221 or the PFRA Shelterbeit Centre in Indian Head at 695-2284.

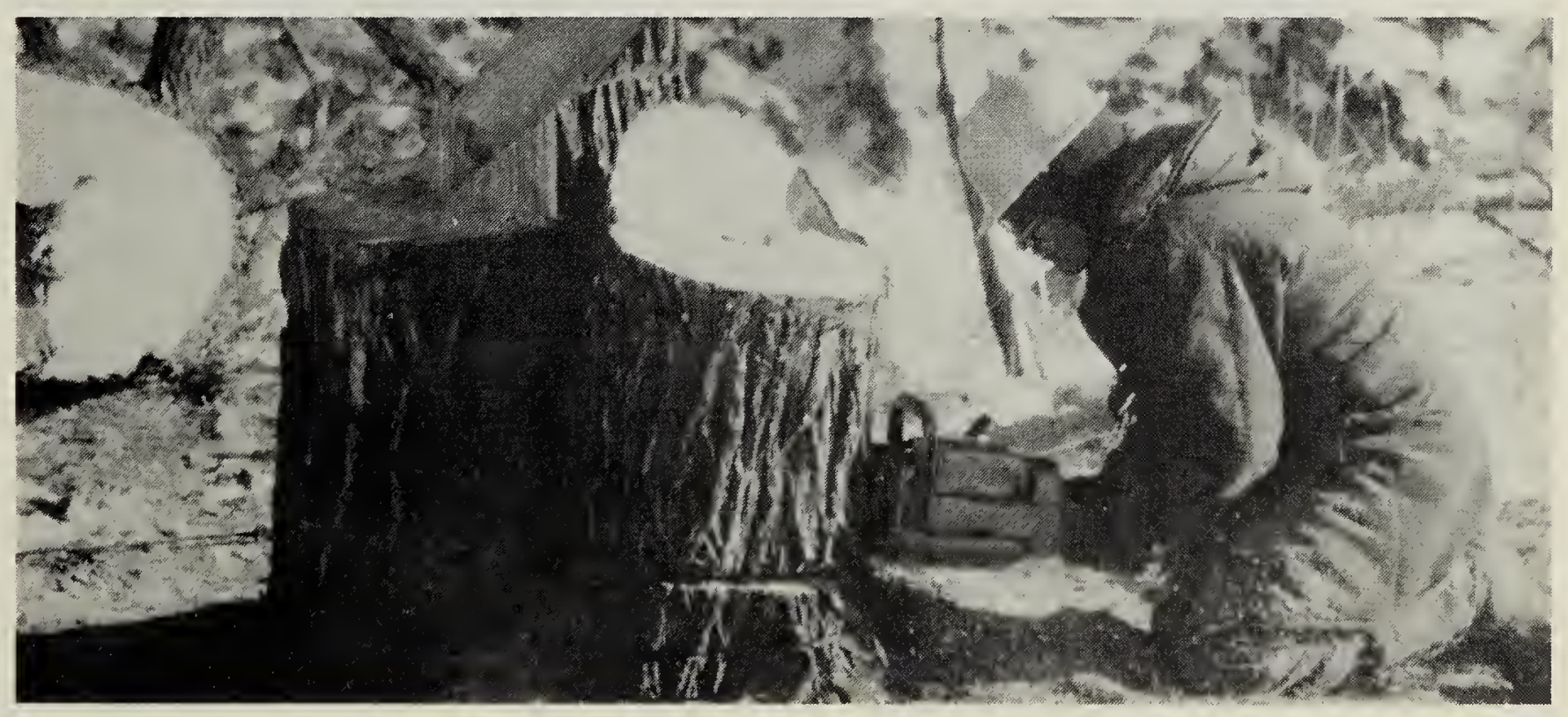

Worker finishes taking down an elm tree infected with Dutch Elm Disease

SPRR 